\title{
O ROMANCE QUE VIROU FILME... QUE VIROU MITO: PENSANDO 0 CORPO A PARTIR DOS 200 ANOS DE FRANKENSTEIN
}

\author{
THE NOVEL THAT HAS TURNED INTO A MOVIE... THAT HAS TURNED INTO A \\ MYTH: THINKING ABOUT THE BODY AFTER 200 YEARS OF FRANKENSTEIN
}

\author{
EL ROMANCE QUE VIRÓ PELÍCULA ... QUE HA VENIDO A MITO: \\ PENSANDO EL CUERPO A PARTIR DE LOS 200 AÑOS DE FRANKENSTEIN
}

\author{
Hamilcar Silveira Dantas Junior ${ }^{1}$ \\ Universidade Federal de Sergipe - UFS \\ Fabio Zoboli2 \\ Universidade Federal de Sergipe - UFS
}

\begin{abstract}
Resumo
Há 200 anos o infortúnio do Dr. Victor Frankenstein e sua "criatura" vem habitando o imaginário cultural mundial. Pelo seu enraizamento social no Ocidente, sua polissemia no campo da arte e seu contínuo processo de repetição/reinvenção, "Frankenstein" também pode ser classificado como um mito da modernidade - principalmente pela sua variação prometeica. O objetivo deste relato de experiência foi descrever acerca dos debates gestados na Mostra de Cinema "Corpo e Modernidade: os 200 anos de Frankenstein" no sentido de apreender as dinâmicas da relação corpo, modernidade e ciência por meio de representações cinematográficas na esteira da herança cultural deste personagem bicentenário. Concluiu-se que o corpo da ciência e da técnica ainda não dá conta de sua proposição de superação.
\end{abstract}

Palavras-chave: Frankenstein; Corpo; Modernidade; Cinema.

\footnotetext{
1 Doutor em Educação pela Universidade Federal da Bahia (UFBA). Professor do Programa de Pósgraduação Interdisciplinar em Cinema da Universidade Federal de Sergipe (PPGCINE/UFS). Professor do Departamento de Educação Física da UFS. E-mail: hamilcarj@bol.com.br. Orcid: http://orcid.org/0000-00034214-0629.

2 Pós-doutor em "Educação do corpo" pela Universidad Nacional de La plata (UNLP/Argentina). Doutor em Educação pela Universidade Federal da Bahia (UFBA). Professor do Programa de Pós-graduação em Educação da Universidade Federal de Sergipe (PPGED/UFS). Professor do Departamento de Educação Física da UFS. Membro do grupo de pesquisa "Corpo e Política". E-mail: zobolito@gmail.com. Orcid: http://orcid.org/0000-0001-5520-5773.
} 


\begin{abstract}
For 200 years the misfortune of Dr. Victor Frankenstein and his "creature" has been inhabiting the world cultural imagination. Due to its social roots in the West, its polysemy in the field of art and its continuous process of repetition / reinvention, "Frankenstein" can also be classified as a myth of modernity - mainly for its Prometheic variation. The purpose of this experience report was to describe the debates that took place at the Cinema Exhibition "Body and Modernity: Frankenstein's 200th Anniversary" in order to grasp the dynamics of the relationship between body, modernity and science through cinematic representations in the wake of the cultural heritage of this bicentennial character. It was concluded that the body of science and technique still does not realize its proposition of overcoming.
\end{abstract}

Keywords: Frankenstein; Body; Modernity; Movie Teacher.

\title{
Resumen
}

Hace 200 años el infortunio del Dr. Victor Frankenstein y su "criatura" viene habitando el imaginario cultural mundial. Por su enraizamiento social en Occidente, su polisemia en el campo del arte y su continuo proceso de repetición / reinvención, "Frankenstein" también puede ser clasificado como un mito de la modernidad - principalmente por su variación prometeica. El objetivo de este relato de experiencia fue describir acerca de los debates gestados en la Muestra de Cine "Cuerpo y Modernidad: los 200 años de Frankenstein" en el sentido de aprehender las dinámicas de la relación cuerpo, modernidad y ciencia por medio de representaciones cinematográficas en la estela de la herencia cultural de este personaje bicentenario. Se concluyó que el cuerpo de la ciencia y de la técnica aún no da cuenta de su proposición de superación.

Palabras clave: Frankenstein; Cuerpo; Modernidad; Cine.

\section{INTRODUÇÃO}

No ano de 2018 comemoraram-se os 200 anos da obra "Frankenstein: o Prometeu moderno" escrita pela jovem inglesa Mary Shelley. O romance relata a estória de Victor Frankenstein, um estudante de ciências naturais que constrói uma criatura a partir de retalhos de corpos mortos retirados das tumbas de um cemitério. Em seu laboratório Victor dá forma à criatura costurando as partes desses corpos que ao final é animada - ganha vida - pela aplicação de "uma centelha de vida na coisa inerte" (SHELLEY, 1999, p. 65)3.

Mary Shelley, ao subintitular seu romance de "Prometeu moderno", faz alusão ao mito grego de Prometeu, que pode ser interpretado como um ato fundante da humanidade

\footnotetext{
3 Posteriormente, graças ao cinema, popularizou-se a versão de que o Dr. Victor Frankenstein incidira choques elétricos para reanimar a criatura, principalmente pela descrição de seus vínculos ao galvanismo então em moda à época de Mary Shelley. Não obstante, a autora não faz na obra nenhuma descrição pormenorizada do laboratório, nem do experimento em si revelando o método utilizado pelo protagonista para dar vida à criatura.
} 
ao esboçar a origem da técnica. O mito conta que Zeus solicitou a Prometeu ${ }^{4}$ e Epimeteu que fizessem os animais e o humano. Quando Epimeteu, ao fazer os animais, esquece de guardar os atributos para fazer do homem um ser completo, Prometeu vai até Zeus e lhe rouba o fogo para corrigir tal incompletude. Metaforicamente ele está munindo o homem da técnica - o instrumento que possibilita aos homens conseguir por si aquilo que doravante suplicavam aos Deuses. Zeus, aborrecido, acorrenta Prometeu a uma rocha onde tem seu fígado eternamente devorado por uma águia. À noite o fígado regenera e no outro dia a ave volta a comê-lo. Não satisfeito, Zeus providencia outro castigo e envia à terra a primeira das mulheres: Pandora. Ela traz para Epimeteu uma caixa onde estão guardados os males que Zeus reservou aos mortais.

O presente de Prometeu, o fogo/técnica, é uma espécie de poder - as capacidades e os meios - pelo qual o homem coloca a natureza a seu serviço, identificando as propriedades e as leis naturais para explorá-las e controlar a sua inserção. O fogo tem o papel de tecnologia divina que introduz no humano - no barro - um conhecimento que o anima - o fogo é assim uma espécie de alma. O fogo é uma tecnologia dominada por técnicas e outras tecnologias, ele é a metáfora perfeita porque é natureza dominada pela técnica, de modo que assim passa a ser uma tecnologia (ZOBOLI e GALAK, 2018, p.3).

Uma das características da modernidade é a substituição da verdade como legado divino para os critérios da ciência como paradigma. A revolução iluminista procurou, como vetor da modernidade, tirar o corpo das mãos de Deus e colocá-lo na mesa para dissecálo e desmontá-lo em partes via postura da ciência metódica. "O saber científico redefiniu o corpo: arrancando-o do homem vivo e escolhendo o cadáver como seu modelo e objeto" (SIBILIA, 2002, p. 68). Assim, este escrito parte do pressuposto de que Frankenstein foi escrito por Mary Shelley a partir de dois argumentos: primeiro, uma desconfiança profunda ao avanço da ciência ao criticar o desejo humano de sermos deuses, de controlar a natureza e produzir a vida artificialmente; e, segundo, por sua motivação de produzir "uma estória que falasse aos misteriosos medos de nossa natureza e despertasse um espantoso horror - capaz de fazer o leitor olhar em torno amedrontado, capaz de gelar o seu sangue e acelerar os batimentos do seu coração" (SHELLEY, 1999, p. 8).

O romance de Shelley gira em torno dessa criatura criada pelo Dr. Victor Frankenstein, que jamais foi nominada e se tornou a representação em si mesma. Ela leva

\footnotetext{
${ }^{4}$ A etimologia do nome Prometeu provém de "pró", antes, e "manthánein", aprender, saber, perceber, ver, significa exatamente o que o latim denomina prudens, de prouidens, o prudente, o "pre-vidente", o que percebe de antemão - o oposto de Epimeteu (BRANDÃO, 1986, p. 166). Por isso Prometeu é o símbolo da ciência na medida em que a ciência projeta - vê antes de fazer - a partir de conhecimentos. Epimeteu simboliza aquele que medita/pensa em demasia tarde.
} 
o nome de seu criador: "o cientista". Aqui já se visualizam alguns litígios que a autora suspende com sua obra: por que o cientista não pôde dar nome a essa "criatura"? Por que Frankenstein é considerado um "monstro"? Em que medida Frankenstein nos faz refletir sobre as inquietações do corpo na modernidade? O que os "retalhos" com que a criatura foi gerada nos fazem pensar sobre os limites/fronteiras de um corpo atravessado pela ciência na modernidade?

Shelley é irônica e providencial quando opta por não dar nome à remendada e malsucedida criação do Dr. Frankenstein que durante a trama ela chama de "monstro", "criatura”, "desgraçado", “abominável”. Ela não o nomeia pois ele pertence à esfera do inclassificável, porque ele está fora do sistema simbólico e, portanto, da inteligibilidade que define as fronteiras entre as categorias do pensamento (LE BRETON, 2005). Por tal motivo, Frankenstein figura como uma obra de terror, afinal, sua natureza é ambígua e por assumir tal condição provoca repulsa, horror e medo. Frankenstein é uma crítica à modernidade, uma crítica aos "feiticeiros" das ciências que manipulam o corpo. "[...] Frankenstein não denomina o monstro, mas o cientista" (COLI, 2003, p. 301): Frankenstein não é o monstro, Frankenstein é o cientista criador de monstros.

A fim de tencionarmos essas questões, a disciplina "Corpo e Educação" - lecionada junto ao Programa de Pós-Graduação em Educação da Universidade Federal de Sergipe (PPGED/UFS) elegeu estudar a obra de Frankenstein para pensar o corpo e a modernidade. Como trabalho final dessa disciplina foi feita uma mostra de cinema que aglutinou também esforços de outros "três lugares": o Departamento de Educação Física, o Programa de Pós-Graduação Interdisciplinar em Cinema (PPGCINE) e o SESC de Aracaju-SE.O objetivo dessa mostra de cinema foi apreender as dinâmicas da relação corpo, modernidade e ciência por meio de representações cinematográficas na esteira da herança cultural do personagem bicentenário "Frankenstein", de Mary Shelley. Assim foram apresentados e debatidos quatro filmes em quatro dias: Frankenstein (James Whale, 1931); Volto já - (episódio da série Black mirror); O médico alemão (Lucia Puenzo, 2013); e, Blade runner, o caçador de andróides (Ridley Scott, 1982). O presente ensaio narra um pouco da experiência dos autores junto à Mostra de Cinema "Corpo e Modernidade: os 200 anos de Frankenstein".

\section{MARY SHELLEY E A OBRA FRANKENSTEIN}

A transição entre os séculos XVIII e XIX na Europa foi preenchida de mudanças drásticas no campo da política, da religião, da literatura, da filosofia, sobretudo das 
orientações das condutas humanas pelo pensamento científico. Os ideais da revolução francesa com sua declaração dos direitos do homem e do cidadão advogando a igualdade entre os sujeitos e a ação do Estado como garantidor dos mesmos, impulsiona à vida prática as aspirações iluministas.

O uso disciplinado da razão e a superação de todo obscurantismo tornam-se a tônica do pensamento europeu à medida que as experimentações de ordem científica se emancipam das artes ocultas ou místicas e se submetem ao crivo do julgamento das instituições acadêmicas. Os experimentos de William Gilbert, Luigi Galvani e Alessandro Volta com o magnetismo e a eletricidade, assim como os de Vesálio e William Harvey na descrição das estruturas anatômicas e de funcionamento do sistema circulatório humano são demarcadores das fronteiras a serem ultrapassadas pelo conhecimento científico.

Nesse contexto cultural efervescente nasce, em 1797, a jovem Mary Wollstonecraft Godwin, filha de dois eminentes literatos. Seu pai, Richard Godwin era um filósofo e escritor de matriz anarquista, enquanto sua mãe, Mary Wollstonecraft, é reconhecida como uma prenunciadora do feminismo por conta de sua obra $A$ vindication of the rights of women, que defendia a necessidade de emancipação das mulheres e que o Estado cessasse sua interferência na vida privada dos sujeitos, o que reforçava as opressões do homem sobre a mulher. Não bastasse a ascendência familiar, aos 16 anos Mary foge de casa para unirse ao poeta Percy Bysshe Shelley, um digno representante do romantismo inglês em sua fase de irreverência e iconoclastia às instituições de sua época. Mary (que já havia publicado um romance infanto-juvenil em 1808) passa a se chamar, Mary Wollstonecraft Shelley e a conviver com os mais profícuos círculos literários da Europa (GUIMARÃES, 2018).

Em uma reunião na Suíça, em fins de 1817, na casa do notório poeta Lorde Byron, os debates literários, as leituras de obras góticas de terror, sobretudo as críticas aos avanços produzidos pelo contexto científico vigente, os poetas presentes lançaram-se ao desafio, proposto por Byron, de escreverem uma história de terror. Tal empreitada foi levada a cabo apenas pela jovem Mary Shelley.

Em oposição ao gênero gótico que se notabilizara por retratar sujeitos depravados, ligados ao sobrenatural, às artes ocultas e místicas, habitantes de lugares sombrios que, por conta de suas maldades e atentados morais, recebiam um castigo divino ao final do enredo, Mary Shelley elaborou o relato das desventuras do Dr. Victor Frankenstein. Sai de cena o sobrenatural para dar vazão à compreensão das motivações psicológicas e sociais da personagem, a saber, o domínio do conhecimento científico, ainda que sob as 
inspirações dos alquimistas da época, para alteração da realidade social. O Dr. Frankenstein será o narrador principal da obra, será a inspiração para a personagem que abre o romance com uma narrativa epistolar: o Capitão Robert Walton. Walton busca ser o primeiro a contornar o Polo Norte enfrentando toda a sorte de adversidades. A narrativa de Frankenstein o fará repensar seriamente dos perigos de enfrentar tão abertamente a Mãe Natureza.

Essa será a tônica da obra de Mary Shelley. Tributária do Movimento Romântico, compreendia a natureza como mãe criadora, viva e ecológica que seria afrontada pela ação do Dr. Frankenstein: dar vida a uma criatura reconstruída por restos mortais de outros humanos. A obsessão da personagem por dominar a relação vida e morte desvela 0 desrespeito às leis de natureza, gera a hybris que desequilibra a vida social e desencadeia a tragédia!

Mary Shelley ao descrever o infortúnio do Dr. Frankenstein - a criação de um ser horrendo composto por retalhos de cadáveres, o abandono de sua criação, a retaliação violenta da criatura que destrói toda sua família e a caça para exterminá-la - estabeleceu as bases da moderna literatura de Ficção Científica: a desconfiança quanto à neutralidade, segurança e boas intenções da ciência, bem como os perigos da humanidade por avançar em terrenos que não são de sua alçada 5 . Não à toa, a autora denomina Frankenstein de Prometeu moderno, posto que a fronteira ultrapassada para subverter a ordem natural não passará incólume à reação da natureza.

Nesse movimento, Mary Shelley produz uma crítica feminina à ciência e sua lógica patriarcal, invasiva à natureza que, todavia, é indomável em sua essência criadora. Victor Frankenstein subverte a natureza ao gerar uma vida, ao renegar sua criação (seu filho), ao negar-Ihe uma companheira, ao condená-lo à solidão, à não-vida. Por outro lado, critica também a sociedade como geradora da maldade humana nas palavras da própria criatura:

Acredita-me, Frankenstein, eu era bom. Minha alma estava cheia de amor pela humanidade; mas não estou só, miseravelmente só? Tu, meu criador, me detestas; que posso, pois, esperar de teus semelhantes, que nada me devem? Eles me desprezam e me odeiam. [...] Se toda a humanidade soubesse da minha existência, faria como tu, armar-se-ia para minha destruição. Não devo, pois, odiar aqueles que me detestam? Não terei

\footnotetext{
${ }^{5}$ Apesar de demonstrar as aspirações legítimas da ciência de seu tempo, Mary Shelley faz uma crítica às mesmas de forte acento religioso, ao tempo que tenciona com a própria religião. A criatura interpela o Dr. Victor Frankenstein comparando-se a Adão ante seu criador. De igual modo, o romance abre com uma epígrafe retirada do célebre poema de John Milton, "Paraíso perdido", do século XVII, sobre a queda dos anjos e dos homens: "Pedi eu, ó meu Criador, que do barro me fizesses homens? Pedi para que me arrancasses das trevas?".
} 
contemplação para com meus inimigos. Eu sou um miserável, e eles devem compartilhar da minha desgraça (SHELLEY, 1999, p. 116).

Essa hybris, esse desequilíbrio da natureza vai gerar a morte de todas as mulheres que cercam o Dr. Frankenstein. Mortes executadas pela criatura, mas causadas pelo egoísmo masculino em querer dominar a tudo, inclusive o que não lhe é natural. Nesse contexto, ao fim e ao cabo, Victor Frankenstein não só não consegue criar vida, mas as destrói!

Essa saga, ainda tão relevante do ponto de vista literário e científico, ainda tão presente no imaginário coletivo do ocidente que comemorou 200 anos em 2018 norteou a Mostra "Cinema, Corpo e Modernidade: os 200 anos de Frankenstein"

\section{SOBRE A MOSTRA DE CINEMA: FRANKENSTEIN 200 ANOS}

A mostra de cinema que é objeto desse ensaio foi pensada a partir da disciplina "Corpo e Educação", oferecida sob o caráter optativo pelos professores Fabio Zoboli e Dinamara Feldens junto ao PPGED-UFS no segundo semestre de 2018. Dessa forma, a mesma foi organizada a partir de 4 obras que em sua narrativa pensam o corpo a partir da modernidade sem perder o fio condutor da mítica de Frankenstein e, por conseguinte, a de Prometeu. Assim, a partir de agora vamos apresentar os filmes e os diálogos que os mesmos estabelecem com a problemática suspensa pela mostra.

O filme que abriu a mostra foi o clássico "Frankenstein" (1931) de James Whale, lançado no ano de 1931. A sinopse do filme o apresenta da seguinte forma:

Henry Frankenstein, um cientista louco, vagueia à noite pelo cemitério procurando membros de diversos cadáveres para costurá-los e formar um único homem, mas para dar vida a este ser monstruoso, um cérebro é necessário. Após uma confusão de Fritz, seu assistente, ele acaba colocando na criatura um cérebro criminoso. Mesmo com sua família e amigos tentando fazê-lo desistir deste experimento, Henry infunde vida na criatura, que escapa para a cidade e começa a causar estragos (FRANKENSTEIN, 1931).

O filme de Whale faz uma série de alterações na história original por se inspirar, primordialmente, na montagem teatral de Peggy Webling, realizada na Inglaterra em 1927, intitulada "Frankenstein, an adventure in the macabre". Homenageando os mestres do expressionismo alemão (Robert Wiene, F.W. Murnau e Fritz Lang) a partir do uso da cenografia, dos enquadramentos e dos jogos de iluminação sombrios, a película de Whale, apesar das radicais licenças narrativas à obra de Shelley, consolidou o imaginário social em torno do mito de Frankenstein (SARTI, 2012). 
A caracterização da criatura com sua cabeça achatada, eletrodos no pescoço, jeito desengonçado e sem articulação linguística, obra da maquiagem de Jack Pierce, sobretudo pela interpretação visceral de Boris Karloff, se tornaria tão icônica a ponto de confundir-se criador e criatura. Ainda que essa obra se abstenha de expor, ou mesmo subtraia completamente, o mito prometeico do debate, a escolha da mesma se justificou posto que a partir daqui, Frankenstein torna-se, no imaginário popular, a criatura não mais o doutor, tornando-se também a protagonista da história. Na cultura pop, Frankenstein, a criatura, circularia o mundo em desenhos animados, revistas em quadrinhos, grupos de rock e uma infinidade de filmes e séries.

O segundo filme da mostra foi o primeiro episódio da segunda temporada da série britânica Black Mirror intitulado "Volto já" (2013). A trama gira em torno da morte de Ash, que deixa viúva sua esposa Martha, a qual, dias depois do velório, descobre estar grávida. Inconsolada, Martha ouve sua amiga falar de um software que traz seu marido de volta num marido virtual a partir das memórias deixadas por ele na rede. Em um primeiro momento, ela considera a ideia absurda, mas depois de baixar dados com informações do cadáver no software, ela começa a falar com o seu marido a partir do "aplicativo".

A empresa criadora do software melhora o serviço e agora apresenta a seus clientes uma versão experimental de outro serviço: um corpo feito de carne sintética onde a memória virtual pode ser descarregada. Em poucos dias Martha tem uma versão póstuma de seu marido na forma de um androide. Com o tempo, Martha vai ficando frustrada com alguns traços emocionais que Ash tinha e que o androide, pela condição de máquina, não consegue reproduzir. Em um salto para sete anos mais, o episódio termina com Martha levando sua filha até o sótão - onde mantém Ash trancado - para comemorar o aniversário dela.

Este episódio de Black Mirror é análogo ao conto de Frankenstein na medida em que Martha devolve a vida a seu marido Ash, não com uma "centelha de vida" ou "choque elétrico", mas com outra forma de "fogo" herdada de Prometeu: foi por meio de códigos de informação que ajudaram a capturar o código genético do falecido para ressuscitá-lo. Com a decifração do DNA - o texto bioquímico que codifica o indivíduo - o corpo passa a ser visto como informação armazenada: chip.

O destino dos homens como máquinas, contudo, estava finalmente inscrito em seus órgãos. Hoje, porém, o panorama mudou: a ordem mecânica que regia inexoravelmente o mundo de acordo com as leis física newtonianas foi desacreditada; o homem e a vida clamam por novas fundamentações. $O$ destino dos seres humanos como feixes de informação parece ter mudado de lócus: agora está inscrito nos genes. A mutação metafórica não é tão sutil 
como parece, e suas implicações podem ser tão vastas (ou tão ínfimas) quanto o próprio homem (SIBILIA, 2002, p. 74).

Zoboli e Galak (2018), em um estudo em que fazem a análise do seriado Blak Mirror sob a perspectiva do mito grego de Prometeu, sustentam o pressuposto de que o seriado Black Mirror apresenta uma perspectiva prometeica trágica frente às relações do corpo com a técnica. Os autores sustentam tal hipótese na medida em que, na maioria dos episódios da série, o corpo manipulado pelas técnicas opta, frente ao enredo trágico criado pela narrativa, retornar a uma condição natural (precária) já superada pelo uso da tecnologia em voga no episódio. Ou seja, a série Blak Mirror pauta-se em uma narrativa onde o homem prefere "recuar sua caminhada em direção a deus" assumindo sua condição de estar "atado às correntes de Zeus".

No terceiro dia da mostra foi exibido o filme da cineasta argentina Lucia Puenzo intitulado "O médico alemão" (2013). O filme foi feito a partir de um romance também escrito por Lucia Puenzo intitulado Wakolda. Assim, o filme gira em torno de uma metáfora: a boneca Wakolda que representa a singularidade feita por um artesão, mas que enfrenta as ambições de um projeto que perpassa toda a narrativa para que se torne uma boneca/corpo projetada, fabricada e montada para ser produzida em série, servindo de metáfora do sonho/pesadelo da ciência moderna em criar corpos perfeitos através do aperfeiçoamento da raça humana - eugenia.

Wakolda representa a tensão entre diferença e homogeneização dos corpos ao propor a fabricação, via o emparelhamento genético, da raça humana. $A$ película está em consonância com a racionalidade moderna de pensar o humano como objeto da ciência, na medida em que a apresenta atravessando o corpo, convertendo-o num laboratório desde onde se podem experimentar técnicas de correção e melhoramento (GALAK, GOMES, ZOBOLI, 2018, p.2)

É uma metáfora na medida em que Wakolda é encenada pela personagem Lilith, uma garota que tem um pequeno problema de crescimento e que vira alvo de um médico alemão refugiado dos campos nazistas. Trata-se de Josef Mengele ${ }^{6}$ que, ao chegar em Bariloche, torna-se hóspede da pensão familiar dos pais de Lilith. O médico alemão representa o sonho da criação de corpos em séries, do uso da ciência para sustentar as políticas modernas que normatizam os usos do corpo e da população.

Com a modernidade nasceu também o direito de exterminar o outro legitimado pela racionalidade biopolítica que autoriza o cadáver via construção da fobia do outro. A

\footnotetext{
6 Josef Mengele é conhecido como "o anjo da morte" por ter sido parceiro de Hitler no projeto de uma Alemanha eugênica. Mengele é cientista nazista que realizou experimentos com humanos no campo de concentração de Auschwitz.
} 
modernidade criou políticas que justificaram o apagamento de corpos sob a certificação da ciência - a modernidade fez "sombras" com suas "luzes".

A mostra fechou com o filme "Blade runner, o caçador de androides" (1982) de Ridley Scott. Em síntese, a película ocorre no ano de 2029, no qual a Terra está superpovoada e em vias de tornar-se inabitável. Tornou-se comum a exploração de outros planetas que possam servir como colônias para os terráqueos. No entanto, preparar esses planetas para a chegada da humanidade precisa de esforços sobre-humanos, por isso a Corporação Tyrrell desenvolve clones humanos, identificados como replicantes: fortes, resistentes, inteligentes, porém com uma existência limitada a quatro anos. Quando um grupo de replicantes se rebela e chega à Terra para procurar seu criador e exigir mais tempo de vida, estabelece-se o terror e um ex-blade runner (caçador de replicantes) é convocado para a missão de deter esse grupo rebelde. Sua jornada implicará em descobrir elementos que norteiam sua própria existência.

No decurso de cinco décadas entre o Frankenstein de James Whale e os replicantes de Ridley Scott, o cinema hollywoodiano já havia explorado à exaustão o mito prometeico de criação, dos perigos de invadir a ordem natural dos fenômenos e de ofender aos deuses. Contudo, Blade Runner tornou-se a culminância da indiferenciação dos limites entre o homem e o artificial, da percepção das capacidades de criação de seres que possam ser humanos em forma, inteligência e sentimentos. Para Sarti (2012), esse filme nos sinaliza uma possibilidade aterradora: se é possível implantar memórias de infância e vínculos familiares na mente de replicantes, se é possível que eles desenvolvam sentimentos diversos a partir dessas memórias, ninguém, absolutamente ninguém, pode estar convicto de sua condição humana.

\section{CONSIDERAÇÕES FINAIS}

A síntese da mostra no percurso entre a obra de Frankenstein e os futuros distópicos imaginados pelo cinema desvelou a profundidade da crítica que Mary Shelley, há 200 anos, nos legou. Diante dos rumos da história da humanidade, a "profecia de Frankenstein", como denominada por Harari (2017), virá se confirmar haja vista que os avanços tecnológicos dos últimos séculos podem conduzir à substituição do Homo Sapiens por seres completamente diferentes, psíquica e emocionalmente. As transformações possíveis na consciência e identidade colocam em suspeição o próprio conceito do "humano" e de sua(s) criação(ões).

\section{REFERÊNCIAS}


BLADE RUNNER, O CAÇADOR DE ANDRÓIDES - Filme. Direção Ridley Scott, EUA, 1982.

BRANDÃO, Junito de Souza. Mitologia Grega (vol. 1). Petrópolis, RJ: Vozes, 1986. COLI, Jorge. O sonho de Frankenstein. In: NOVAES, Adauto (org.). O homem-máquina: a ciência manipula o corpo. São Paulo: Companhia das letras, p. 299-316, 2003.

FRANKENSTEIN - Filme. Direção James Whale, EUA, 1931.

GALAK, Eduardo. De projetos da ciência à fabricação em série: educação do corpo, biopolítica e eugenia em Wakolda. Acta Scientiarum Education, v. 40(4), p.1-10, 2018.

GUIMARÃES, Armando Rui. Mary Shelley: vida e obra. In: ARAÚJO, A.F.; ALMEIDA, R.; BECCARI, M. O mito de Frankenstein: imaginário e educação. São Paulo: FEUSP, 2018. p. 32-70.

HARARI, Yuval Noah. Sapiens: uma breve história da humanidade. 29. Ed. Porto Alegre: L\&PM, 2017.

LE BRETON, David. A síndrome de Frankenstein. In: SANT'ANNA, Denise Bernuzzi (org.). Políticas do corpo. 2 ed. São Paulo: Estação liberdade, p. 49-68, 2005.

O MÉDICO ALEMÃO - Filme. Direção Lúcia Puenzo. Argentina, 2013.

SARTI, Graciela C. Autómata: el mito de la vida artificial en la literatura y el cine. Buenos Aires: Editorial de la Facultad de Filosofia y Letras Universidad de Buenos Aires, 2012.

SHELLEY, Mary. Frankenstein: o Prometeu moderno. Porto Alegre: L\&PM, 1999.

SIBILIA, Paula. O homem pós-orgânico: corpo, subjetividade e tecnologias digitais. 2. Ed. Rio de Janeiro: Relume Dumará, 2002.

VOLTO JÁ - 1 episódio da 2 série de Black Mirror. Direção Charlie Brooker, GrãBretanha, 2013.

ZOBOLI, Fabio; GALAK, Eduardo. Prometeu, Epimeteu e Pandora: corpo, técnica e tecnologia em "black mirror". Revista Art\&Sensorium, Curitiba, v.5, n.1, p. 1-15. Jan.-Jun. 2018. 